\title{
200 AÑOS DE DESARROLLO JURÍDICO EN EL CHILE REPUBLICANO. NOTAS PARA UN BALANCE
}

\author{
200 YEARS OF LAW DEVELOPMENT IN REPUBLICAN CHILE. NOTES FOR \\ A BALANCE
}

\section{Cristóbal García-Huidobro Becerra ${ }^{1}$.}

Siempre los aniversarios resultan un momento especial para realizar balances; para detenernos en el camino y reflexionar hasta dónde hemos llegado y en qué condiciones. Desde el punto de vista del Derecho, el advenimiento del bicentenario de nuestro primer gobierno nacional se convierte en una de aquellas oportunidades que nos permiten realizar un recuento de la evolución que han tenido las instituciones jurídicas en nuestro país. Esto resulta aún más relevante, toda vez que entendemos al Derecho como un reflejo -aunque imperfecto- de la evolución institucional de los países. Como realidad material, el Derecho no es en esencia algo estático, sino dinámico y adaptable a las demandas del cuerpo social. Así entonces, el estudiarlo y ponderarlo desde una perspectiva histórica se vuelve una tarea fundamental para comprender la evolución de Chile como Estado y como sociedad.

Desde los primeros pasos dados en 1810 hacia la formación de nuestro primer gobierno nacional, la necesidad de dotar a Chile de un estatuto jurídico vernáculo se convirtió en una preocupación permanente de las nuevas autoridades nacionales ${ }^{2}$.

1 Coordinador General de la Revista Chilena de Derecho. D.Phil (c) in History, University of Oxford; Licenciado en Historia y egresado de Derecho, Pontificia Universidad Católica de Chile. Profesor de Historia del Derecho, Universidad Alberto Hurtado.cagarcib@uc.cl

2 ROLDÁN, Alcibiades; "Las primeras asambleas nacionales: años 1811 a 1814 ”, Santiago, Imprenta Gutenberg, 1890 , pp. 6-7. Véase también, a modo de consulta, EDWARDS, Alberto "La organización política de Chile”, Santiago, Editorial del Pacífico, 1955, passim; HeISE, Julio, "150 años de evolución institucional”, Santiago, Editorial Andrés Bello,
En 1811 se reunió el Primer Congreso Nacional de Chile, como asamblea legislativa representativa, y ese mismo año se promulgó el primero de una serie de reglamentos constitucionales que vendrían a ser la primera expresión del Derecho Público nacional, y en el caso particular del reglamento constitucional de 1812, contendría la primera expresión real de soberanía al establecer su artículo $5^{\circ}$ que "ningún decreto, providencia u orden, que emane de cualquier autoridad o tribunales de fuera del territorio de Chile, tendrá efecto alguno; y los que intentaren darles valor, serán castigados como reos del Estado" 3 . El proyecto de reglamento de Juan Egaña (1813) y el reglamento provisional de 1814 siguieron un patrón similar, sentando las bases del derecho constitucional chileno. Posteriormente, luego de alcanzada la independencia en 1818 , la dictación de la Constitución provisoria de 1818 y la Constitución de 1822 reflejaron el espíritu doctrinario de los revolucionarios independentistas: libertad, igualdad, propiedad, responsabilidad y seguridad. Estos eran los principios fundamentales que inspiraron los movimientos revolucionarios en América Latina ${ }^{4}$, incluyen-

1960, pp. 9-43; EYZAGUIRRE, Jaime "Fisonomía Histórica de Chile", Santiago, Editorial del Pacífico, 1965, pp. 91-135, y Collier, Simon "Chile: La construcción de una república 1830-1865”, Santiago, Ediciones de la Universidad Católica de Chile, 2005, pp. 23-83.

3 Cfr. Reglamento Constitucional Provisorio del Reyno de Chile, 1812.

${ }^{4}$ LYNCH, John: "Las Revoluciones Hispanoamericanas. 1808-1826”, Editorial Ariel, Barcelona, 1976, pp. 80 y ss. Véase también Ávila, Alfredo; "Las revoluciones hispanoamericanas vistas desde el siglo XXI", en Revista de Historia Iberoamericana, 2008, volumen $1, n^{\circ} 1$, pp. 12 y ss. 
do Chile. Son, en su esencia, la base de los derechos llamados "de primera generación" o derechos políticos clásicos y que se plasmaron con fuerza relativa en todas las cartas fundamentales chilenas durante el siglo XIX ${ }^{5}$.

Si bien el derecho público nacional fue el primero en florecer, el derecho privado tardó más en encontrar su materialización, aunque su inspiración siempre estuvo de la mano de la tradición del derecho continental y del proceso codificador que se remonta al último tercio del siglo XVIII ${ }^{6}$. Así entonces, bajo la égida de Andrés Bello y Mariano Egaña ${ }^{7}$, se inició un proceso que buscaba crear un sistema de derecho privado moderno y republicano, que tomase lo mejor de la tradición clásica, integrándola a su vez con las corrientes más en boga del escenario jurídico de la épo-

${ }^{5}$ Heise, Julio: Historia constitucional de Chile, Santiago, Editorial Jurídica de Chile, 1959, pp. 29-38 y 47-57. Al respecto pueden revisarse los capítulos correspondientes a garantías y derechos de las constituciones de 1822, 1823, el proyecto de constitución federal para el Estado de Chile de 1827, la Constitución de 1828 y la promulgada en 1833 . Con respecto al proyecto de constitución federal, este se encuentra en LETELIER, Valentín: Sesiones de lo cuerpos legislativos, Santiago, Imprenta Cervantes, 1891, volumen XIV, pp. 65-75. Véase para las Constituciones de 1828 y la de 1833 DONOSO NOvOA, Ricardo: "José Joaquín de Mora y la Constitución de 1828", en Revista Chilena de Historia del Derecho No 1, 1959; Cifuentes, José María: "La Constitución de 1833", en Boletín de la Academia Chilena de la Historia No 1, 1933, y BraVo LIRA, Bernardino: El estado de derecho en la historia de Chile, Santiago, Ediciones Universidad Católica de Chile, 1996.

6 Merryman, John Henry: Sistemas Legales en América Latina y Europa. Tradición y Modernidad, México D.F. Fondo de Cultura Económica, 1990. Véase el Capítulo V titulado Los Códigos y la Codificación.

7 Véase GuZMÁn Brito, Alejandro (editor), El proyecto no completo de un Código Civil para Chile, escrito por el señor D. Mariano Egaña: (primer proyecto de Código Civil de Chile), Santiago, Editorial Jurídica de Chile, 1978, y BELLO, Andrés: Proyecto de Código Civil, Santiago, Editorial Nascimento, 1932, 3 volúmenes. $\mathrm{ca}^{8}$. Así, entonces, terciando la última década de la primera mitad del siglo XIX, el proceso codificador en Chile dio a luz nuestro Código Civil, tomado como modelo jurídico por otras naciones latinoamericanas ${ }^{9}$, y que fue el primer eslabón de todo un movimiento de creación jurídica codificada que se extendería por los próximos veinte años: los códigos de Comercio (1865) y Penal (1875) vinieron a regular materias que hasta ese entonces encontraban su base, para el caso del derecho mercantil, en la costumbre; y en el caso del derecho penal en la legislación indiana o la pluralidad de decretos y leyes que regulaban la fuerza punitiva del Estado. El mismo año 1875 se promulgó la Ley Orgánica de Tribunales, fundamento del futuro Código Orgánico de Tribunales. Ya iniciado el siglo XX, los Códigos de Procedimiento Civil (1893) y de Procedimiento Penal (1906) vendrían a cerrar el proceso de codificación nacional.

Sin embargo, con el nuevo siglo nuevas preocupaciones surgieron de parte de los legisladores en vista de la crítica situación que se vivía en los centros urbanos de nuestro país. En los últimos veinte años del siglo XIX, Chile había entrado en un periodo de prosperidad económica, con abundancia de capitales y recursos productivos; lo que a su vez generó demandas por mano de obra, ya fuera para el sector productivo como también en el sector de servicios. Así entonces fue como empezó a gestarse la llamada "Cuestión Social", y de la mano de esta una serie de demandas por soluciones concretas a la miseria rampante de una parte importante de los chilenos.

Durante por cerca de quince años una serie de piezas de legislación social fueron promulgadas en Chile con el fin de servir de cortapisas a la dramática situación de desamparo de una parte considerable de la población urbana del país. En 1906 se aprobó la ley no

\footnotetext{
${ }^{8}$ Lira, Pedro: El código civil chileno y su época, Santiago, Editorial Jurídica de Chile, 1956, pp. 20 y ss.

${ }^{9}$ GUZMÁN BRITO, Alejandro et al.: "De la codificación a la descodificación. Code Civil (18042004) Código de Bello (1855-2005)", Santiago, Ediciones de la Universidad Diego Portales, 2005.
} 
1.838 sobre habitaciones obreras, seguida por otra que establecía y regulaba el descanso dominical, y en 1912, el gobierno del presidente Ramón Barros Luco promulgó la ley no 2.675 sobre protección a la infancia desvalida. Siguiendo con el esfuerzo legislativo en materia social, en 1914 se promulgó la llamada "Ley de la Silla"10 y en 1916 la ley no 4.055 sobre accidentes del Trabajo, y en 1918 nace a la vida del derecho la primera ley en materia de pensiones, destinada a los empleados de ferrocarriles.

Pero dicho sea de paso, el proceso de socialización del Derecho en Chile no quedó solamente en sede de leyes, sino que también continuó su avance hacia estadios de mayor fuerza legislativa, como ya se venía produciendo en otras partes del mundo. Así entonces en 1925, con la promulgación de una nueva Constitución Política de la República el 18 de septiembre de ese año, se integró al acervo constitucional una serie de garantías fundamentales en materia social: protección al trabajo, salud pública y libertad de enseñanza -entre otras- fueron normas que convirtieron al texto constitucional de 1925 en la primera Constitución chilena en garantizar derechos políticos y sociales para toda la población ${ }^{11}$. Estas materias fueron el inicio de un proceso de apertura y democratización que eventualmente permitió incorporar a la mujer dentro del proceso electoral, primero en las elecciones de alcaldes y regidores en 1935 y luego con la concesión del voto en elecciones legislativas y presidenciales en 1949. La reducción de la mayoría de edad de 21 a 18 años y la concesión del voto a personas con discapacidad y analfabetas fueron otros pasos legislativos que se ins-

${ }^{10}$ La ley no 2.951 , conocida también como "Ley de la Silla”, establecía en su artículo primero que "En los almacenes, tiendas, bazares, bodegas, depósitos de mercaderías y todos los establecimientos comerciales semejantes, el patrón o empresario mantendrá el número suficiente de asientos o sillas a disposición de los dependientes o empleados".

11 Cfr. Constitución Política de la República de Chile, promulgada del 18 de septiembre de 1925 . En particular, consúltese el capítulo III sobre "garantías fundamentales". criben dentro de este proceso de apertura a nivel jurídico-constitucional.

Finalmente, un hito fundamental dentro de nuestra evolución jurídica ha sido la promulgación de la Código Político de 1980. Incluyendo en su texto la tradición jurídica nacional, la Constitución de 1980 reforzó principios fundamentales de nuestro ordenamiento, como la primacía de la persona humana, la servicialidad del Estado, el principio de subsidiariedad; y mediante sucesivas reformas a su texto -la última en 2005-, reforzó los mecanismos de control sobre los órganos del Estado, ampliando, por ejemplo, las facultades de fiscalización del Poder Legislativo por sobre el Ejecutivo y las del Tribunal Constitucional en cuanto al conocimiento del recurso de inaplicabilidad.

Pero ahora cabe hacerse la pregunta ¿qué desafíos depara el futuro al derecho chileno? Sin duda deberemos enfrentar las mareas de la globalización a nivel jurídico, intentando conciliar el derecho propio frente a una creciente tendencia a la internacionalización del Derecho; entregarnos con prudencia pero sin temor a la exploración de nuevas perspectivas del derecho, primordialmente en materias de desarrollo tecnológico y comunicaciones, y finalmente tomar posición en cuanto a la regulación de materias relacionadas con los llamados "derechos de tercera generación" y el desarrollo de la ciencia médica y la biología, especialmente en el campo de la bioética. Sin duda, el abordar dichos desafíos no será algo pacífico, sino turbulento, pero abre oportunidades para repensar y reafirmar la tradición jurídica construida en Chile, ya con armonía, pero también con sus bemoles, en estos últimos 200 años. 
